\title{
Antipenetration Performance of Honeycomb Shelter under Two Repeat Projectile Strikes
}

\author{
Qifan Wang, ${ }^{1}$ Liusheng Chu $\mathbb{D}^{2},{ }^{2}$ Jie Li, ${ }^{3}$ Jianhu Sun, ${ }^{1}$ Sheng Luo, ${ }^{1}$ and Lei Mao ${ }^{1}$ \\ ${ }^{1}$ Department of Civil Engineering, Army Logistics University, Chongqing 401311, China \\ ${ }^{2}$ School of Civil Engineering, Zhengzhou University, Zhengzhou 450001, China \\ ${ }^{3}$ CMCU Engineering Co, Ltd., Chongqing 400500, China \\ Correspondence should be addressed to Liusheng Chu; cls981@163.com
}

Received 6 May 2020; Revised 2 August 2020; Accepted 25 August 2020; Published 18 September 2020

Academic Editor: Xiaonong Guo

Copyright (C) 2020 Qifan Wang et al. This is an open access article distributed under the Creative Commons Attribution License, which permits unrestricted use, distribution, and reproduction in any medium, provided the original work is properly cited.

\begin{abstract}
Antipenetration performance of honeycomb shelter under two repeat projectile strikes is investigated via test and numerical simulation. Among them, there are two kinds of test targets: cylindrical honeycomb structure target and reinforced concrete target; a numerical simulation target is a honeycomb-structure target composed of hexagonal honeycomb unit, and the size of the target is the same as that of the honeycomb-structure target in test. The results show that the damage area of the honeycombstructure target is smaller than that of the reinforced concrete target under projectile strikes with approximately the same velocity. The damage range of the honeycomb-structure target is limited within the hexagonal cell getting contact with projectile left other cells with no damage. During the two repeat projectile strikes, the first projectile will deflect to some extent just as single projectile strike. The deflection of the second projectile is larger and is related to the distance between the strike points of the two projectiles. The results show that honeycomb shelter performs good under two repeat projectile strikes.
\end{abstract}

\section{Introduction}

Relationship between weapons and protection engineering is like the relationship between spear and shield. In recent years, precision-guided weapons are getting higher in precision and larger in damage capability, [1] which lead to protection technology getting greatly developed. Therefore, in the fight against protection engineering nowadays, repeated strikes of weapons are needed to destroy the target engineering as single strike cannot destroy engineering especially deeply buried type [2]. In the Gulf War, the U.S. military had to fire two precision-guided weapons with the same trajectory to destroy underground protection engineering. In the Iraq war, an underground command center in Iraq was finally destroyed under 4 repeated penetration weapon strikes [3]. In the future, repeated strikes will be one of the major threats to the important protection engineering in war.

Concrete, metal, and other conventional materials are often unable to meet the protect requirements as for repeated strikes. The multilevel porous structure in nature provides a way to solve the problem. Under the environment of the survival of the fittest in nature, these organisms form specific porous structures adapted to the changes of nature and get preserved, which show excellent impact resistance mechanical properties. As a typical regular porous structure, the honeycomb structure is inspired by honeybee's honeycomb. Scholars have carried out a lot of research on the impact resistance of this kind of honeycomb material. $\mathrm{Hu}$ et al. have studied the influence of hexagonal angle on impact performance [4], Shi et al. have studied the mechanical behavior of honeycomb and its sandwich structure under impact load [5], Shi et al. have studied the influence of loading direction on deformation mode and energy absorption characteristics of honeycomb under in-plane and out of plane loading [6], Shi et al. discussed the influence of cell irregularity and impact velocity on the honeycomb deformation mode [7], and Wang et al. carried out numerical simulation and experimental research on the single penetration performance of the honeycomb baffle structure 
[8-11], mainly focusing on the single penetration performance of the honeycomb structure.

According to the current research situation, there are few research studies on the antirepeated penetration of the honeycomb structure. Repeated penetration research mainly considers the damage effects such as crater and damage area size formed by projectile penetration, which can provide research basis and experimental verification for subsequent explosion effect analysis [12]. In this paper, a kind of shielding structure composed of hexagonal concrete-filled steel tube is taken as the research object in this paper.

\section{Test and FEM Simulation Specification}

2.1. Test Specification. Projectiles used in the tests (Figure 1) are made of $40 \mathrm{CrNiMoA}$ alloy with the following specification:

\section{Length: $70 \mathrm{~mm}$ \\ Diameter (middle): $10 \mathrm{~mm}$ \\ Ratio of length to diameter: 7 \\ Diameter (within $60 \mathrm{~mm}$ length to the tail end): $15 \mathrm{~mm}$}

The compressive strength of concrete and the tensile strength of steel used in the tests are $90 \mathrm{MPa}$ and $370 \mathrm{MPa}$, respectively. The thickness and diameter of the target are $200 \mathrm{~mm}$ and $640 \mathrm{~mm}$, respectively. The target used in tests fall into two categories, namely, Honeycomb Shelter Target (HST for short, as shown in Figure 2) and Reinforced Concrete Target (RCT for short, as shown in Figure 3). HST is a short cylinder with diameter of $640 \mathrm{~mm}$ and height of $200 \mathrm{~mm}$ mainly composed of 7 concrete-filled steel tubes with hexagonal section, as shown in Figure 2. Each tube is made of $4 \mathrm{~mm}$ thickness steel plate with length of $120 \mathrm{~mm} \times 6$ and width of $200 \mathrm{~mm}$ which means the tube is with 6 sides of $120 \mathrm{~mm}$ in sectional plane and height of $200 \mathrm{~mm}$. RCT is also a short cylinder with diameter of $640 \mathrm{~mm}$ and height of $200 \mathrm{~mm}$. Two layers of $70 \mathrm{~mm} \times 70 \mathrm{~mm}$ steel nets made of $18 \mathrm{~mm}$ diameter bar are set at planes off upper and lower surface of the cylinder, respectively, as shown in Figure 3.

Figure 4 is test arrangement diagram, and from the left to the right are the projectile launcher, speed measuring device, and target, respectively. Projectile speed can be adjusted by changing the amount of gunpowder charged in the projectile launcher. The speed measuring device is composed of a timer and two pieces of tinfoil arranged perpendicular to projectile trajectory with a fixed distance. Projectile speed can be calculated by distance between the two pieces of tinfoil and time of projectile moving between the two pieces of tinfoil recorded by the timer.

2.2. FEM Model Specification. The projectile is modeled with the same size as projectile used in tests by Design Modeler platform in ANSYS Workbench. The projectile model is meshed with size control ( $4 \mathrm{~mm}$ in size), as shown in Figure 5. Parameters for 40CrNiMoA alloy in AUTODYN are used for the projectile model. Johnson-Cook material strength model and linear equation of the state are also used

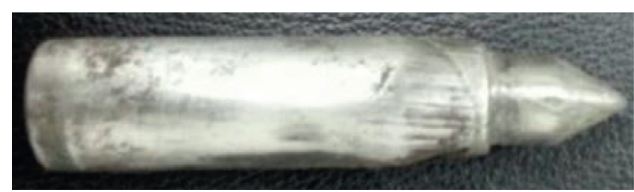

Figure 1: Projectile used in test.

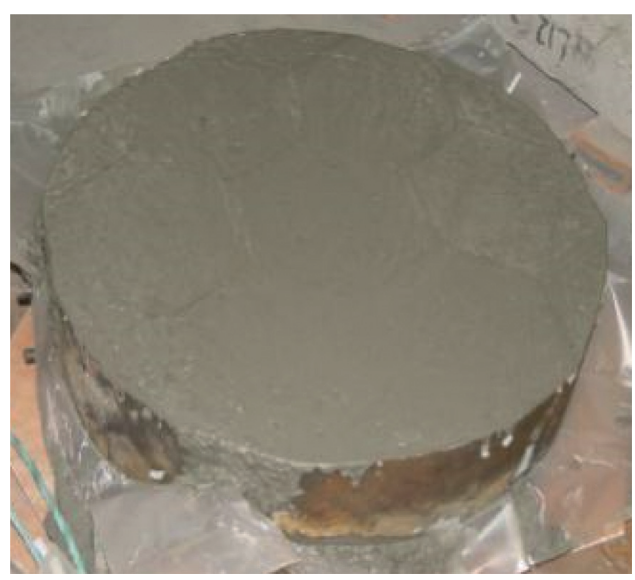

FIgURE 2: Honeycomb shelter target diagram.

for the projectile model. Johnson-Cook strength model is mainly used to describe materials under large deformation, large stress, and high temperature. In this strength model, the yield stress of the material is expressed as

$$
\sigma_{y}=\left(A+B \varepsilon_{p}^{n}\right)\left(1+C \varepsilon_{p}^{*}\right)\left(1-\left(\frac{\theta-\theta_{t}}{\theta_{\text {melt }}-\theta_{t}}\right)^{m}\right),
$$

where $\sigma_{y}$ is the yield stress of the material, $A$ is the yield stress of the material under small deformation, $B$ is the hardening constant, $\varepsilon_{p}$ is the effective plastic strain, $n$ is the hardening index, $C$ is the strain rate constant, $\varepsilon_{p}$ is the effective plastic strain rate, $\theta_{\text {melt }}$ is the melting temperature, and $\theta_{t}$ is the conversion temperature. In the linear equation of state, the material density, shear modulus, bulk modulus, and other parameters are also needed. The specific values of parameters are shown in Table 1.

The HST is modeled with the same size as target used in tests by Design Modeler platform in ANSYS Workbench. The volume sweep mesh method is adopted while generating finite element. Concrete within steel tube centered in HST is with more intensive mesh ( $4 \mathrm{~mm}$ in size) for later contact with projectile, as shown in Figure 6.

As the steel tube is made of low carbon steel, the Johnson-Cook material strength model, linear equation of state, and Johnson-Cook material failure model are used to describe the steel plate in numerical simulation, and related parameters are listed in Table 2.

The JH-2 material model is adopted for concrete in AUTODYN which is described by the Johnson-Holmquist strength model, polynomial equation of state, and Johnson-Holmquist failure model.

It is difficult to determine the parameters of polynomial equation of state by experiment, so the parameters of 


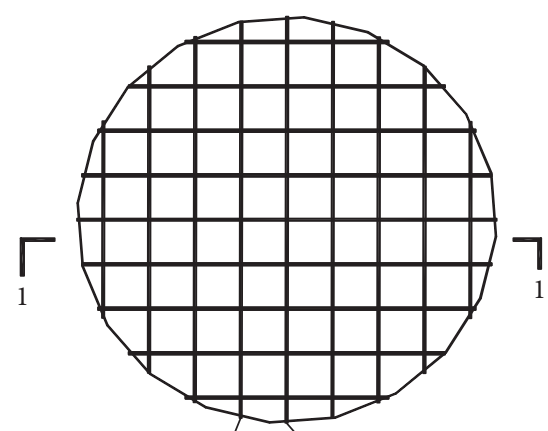

(a)

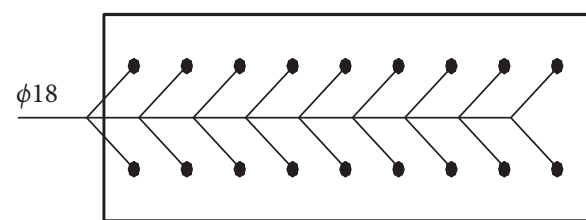

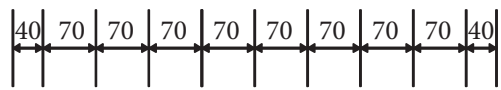

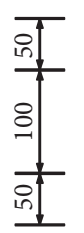

(b)

Figure 3: Steel nets in RCT: (a) front view and (b) 1-1 section view.

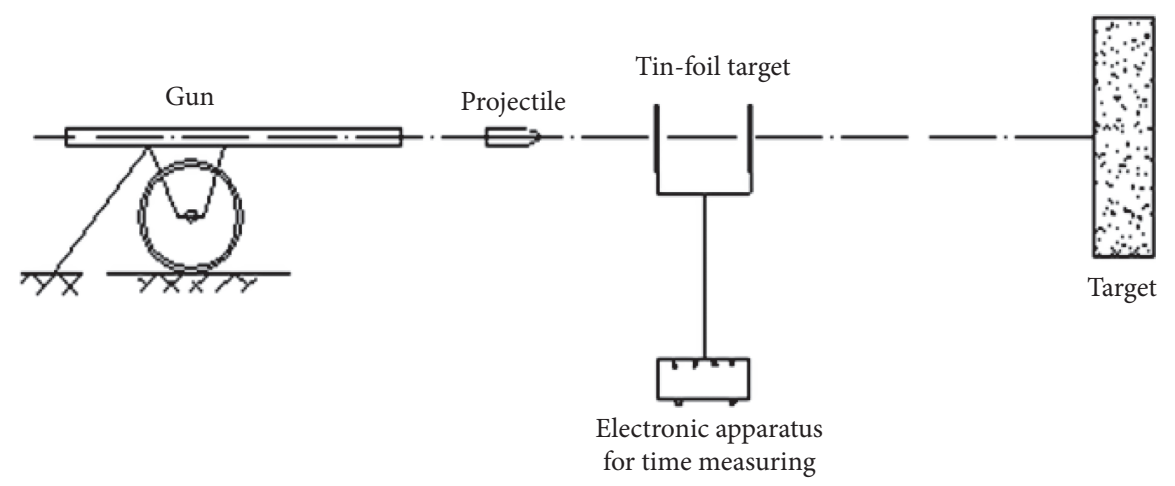

Figure 4: Test arrangement diagram.

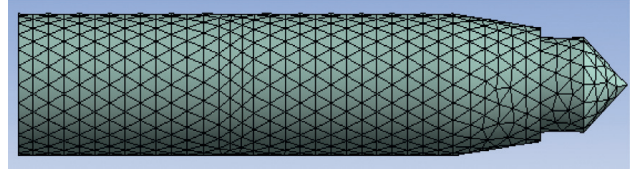

Figure 5: FEM model of projectile.

TABLE 1: Material parameters of the projectile body model.

\begin{tabular}{lccccccc}
\hline $\begin{array}{l}\rho(\mathrm{kg} / \\
\left.\mathrm{m}^{3}\right)\end{array}$ & $\begin{array}{c}G \\
(\mathrm{GPa})\end{array}$ & $\begin{array}{c}K \\
(\mathrm{GPa})\end{array}$ & $\begin{array}{c}A \\
(\mathrm{GPa})\end{array}$ & $\begin{array}{c}B \\
(\mathrm{GPa})\end{array}$ & $n$ & $C$ & $m$ \\
\hline 7.83 & 81.8 & 159 & 0.792 & 0.51 & 0.26 & 0.014 & 1.03 \\
\hline
\end{tabular}

concrete equation of state adopt default parameters. The parameters of the Johnson-Holmquist strength model include shear modulus, Hugoniot elastic limit, intact strength coefficient $A$, intact strength index $N$, strain rate constant $C$, failure strength coefficient $b$, failure strength index $M$, and maximum failure strength ratio. The parameters in the failure model include hydrostatic tensile strength ratio, damage coefficient, volume expansion coefficient, principal tensile failure stress, maximum equivalent strength, and crack-extended energy rate. These parameters are mainly determined according to the test, literature, and relevant concrete specifications [9-12]. The concrete model parameters used for numerical simulation are shown in Table 3.

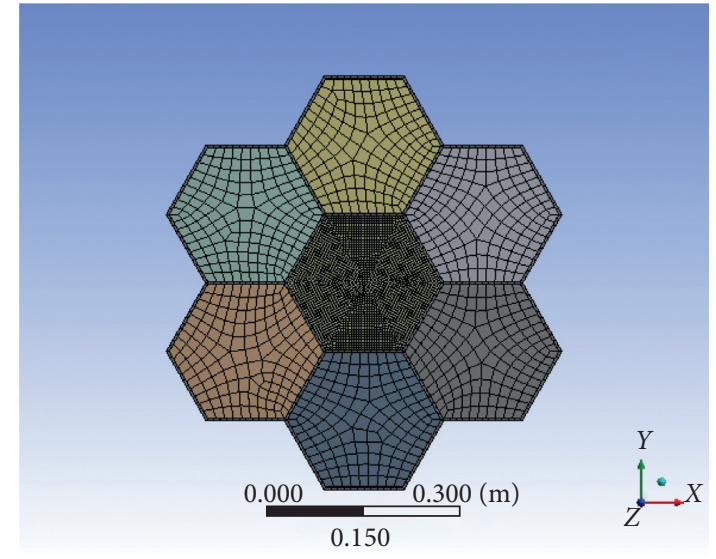

Figure 6: FEM model of HST.

TABle 2: The material parameters of the steel plate model.

\begin{tabular}{lcccccc}
\hline$\rho\left(\mathrm{kg} / \mathrm{m}^{3}\right)$ & $G(\mathrm{GPa})$ & $K(\mathrm{GPa})$ & $A(\mathrm{GPa})$ & $B(\mathrm{GPa})$ & $n$ & $C$ \\
\hline 7.83 & 81.8 & 159 & 0.792 & 0.51 & 0.26 & 0.014 \\
$m$ & $D_{1}$ & $D_{2}$ & $D_{3}$ & $D_{4}$ & $D_{5}$ & \\
1.03 & -2.2 & 5.43 & -0.47 & 0.016 & 0.63 & \\
\hline
\end{tabular}

\section{Results}

3.1. Test Results. Penetration tests are carried out with HST and RCT and the penetration direction is perpendicular to target surface in all tests. The main parameters 
TABle 3: The JH-2 model of parameters of the concrete.

\begin{tabular}{lccccc}
\hline$\rho\left(\mathrm{g} / \mathrm{cm}^{3}\right)$ & $K(\mathrm{GPa})$ & $G(\mathrm{GPa})$ & HEL $(\mathrm{MPa})$ & $A$ & \multicolumn{1}{c}{. } \\
\hline 2.5 & 20.45 & 20.09 & 105.81 & 0.79 & 0.63 \\
$C$ & $B$ & $M$ & MFSR & HTL $(\mathrm{MPa})$ & $D_{1}$ \\
0.007 & 1.61 & 0.63 & $1 E 20$ & -6.46 & 0.04 \\
$D_{2}$ & BCB & TF & PTFS $(\mathrm{MPa})$ & $\mathrm{MP} / 2(\mathrm{MPa})$ & $\mathrm{Gf}\left(\mathrm{J} / \mathrm{m}^{2}\right)$ \\
1.0 & 1 & Principal & 8.85 & $1 \mathrm{E} 20$ & 116.4 \\
\hline
\end{tabular}

TABle 4: Test results.

\begin{tabular}{|c|c|c|}
\hline $\begin{array}{l}\text { Target } \\
\text { number }\end{array}$ & $\begin{array}{l}v_{1}, v_{2} \\
(\mathrm{~m} / \mathrm{s})\end{array}$ & Target failure description \\
\hline \multirow{2}{*}{ HST1 } & & $\begin{array}{l}\text { Front surface: obvious funnel pit is observed and the damage area is about } 374 \mathrm{~cm}^{2} \text {; one of the projectiles does not } \\
\text { penetrate the target; cracks and other damages are not observed in other cells }\end{array}$ \\
\hline & 782.3 & $\begin{array}{c}\text { Rear surface: obvious funnel pit is observed and the damage area is about } 385 \mathrm{~cm}^{2} \text {; cracks and other damages are not } \\
\text { observed in other cells }\end{array}$ \\
\hline \multirow{2}{*}{ HST2 } & 318 & $\begin{array}{l}\text { Front surface: obvious funnel pit is observed and the damage area is about } 390 \mathrm{~cm}^{2} \text {; cracks and other damages are } \\
\text { not observed in other cells }\end{array}$ \\
\hline & 691.8 & $\begin{array}{c}\text { Rear surface: obvious funnel pit is observed and the damage area is about } 380 \mathrm{~cm}^{2} \text {; cracks and other damages are not } \\
\text { observed in other cells }\end{array}$ \\
\hline \multirow[b]{2}{*}{ RCT1 } & 354.7 & Front surface: obvious funnel pit is observed and the damage area is about $2830 \mathrm{~cm}^{2}$; There are 6 obvious cracks \\
\hline & 782.0 & $\begin{array}{c}\text { Rear surface: obvious funnel pit is observed whose depth is } 9 \mathrm{~cm} \text { and the damage area is about } 4300 \mathrm{~cm}^{2} \text {; there are } 17 \\
\text { obvious cracks }\end{array}$ \\
\hline
\end{tabular}

and test results are listed in Table 4 , where $v_{1}$ and $v_{2}$ stand for speed of the first and second projectile, respectively. Front surface is the cylinder surface face to the projectile launcher and rear surface is the other surface of the cylinder.

Damage area of HST is smaller than that of RCT as concrete compressive strength and other performance getting improved due to restraint effect of the hexagon steel pipe surrounded. HST is divided into some cell by the hexagon steel pipe so that damage in one cell will have little influence on neighboring cells. Damage in HST will be restrained within cell getting contact with the projectile and no radioactive crack will appear. Damage of targets after tests is shown in Figure 7.

3.2. Simulation Results. Based on test results, damage in a certain cell has little influence on neighboring cells. In numerical simulation of HST under two repeat projectile strikes, two projectiles will strike at two locations within the same cell. Velocity and impact point location of projectile specifications are listed in Table 5.

In order to figure out the stress condition of the target during the projectile penetration process, several Gauge units are selected to get pressure-time history. 10\# and 11\# Gauge units belong to concrete within the cell getting contact with projectile. 14\# and 15\# Gauge units belong to concrete within the neighboring cell. 18\# Gauge unit belongs to the middle steel pipe. 10\#, 11\#, 14\#, and 18\# Gauge units are within the same plane. The numerical simulation results under different configurations are shown in Figures 8-11.

\section{Discussion}

4.1. Analysis of Target Damage Area. It can be found from the test results that damage area of HST is far smaller than that of RCT under projectiles with appropriately the same velocity. While impact points of two projectiles with velocity $377.9 \mathrm{~m} /$ $\mathrm{s}$ and $782 \mathrm{~m} / \mathrm{s}$, respectively, are within the same cell in HST1, the damage area in the front surface and rear surface are $374 \mathrm{~cm}^{2}$ and $385 \mathrm{~cm}^{2}$, respectively. While impact points of two projectiles with velocities $318 \mathrm{~m} / \mathrm{s}$ and $691.8 .4 \mathrm{~m} / \mathrm{s}$, respectively, are within different cells in HST2, the damage area in the front surface and rear surface are $390 \mathrm{~cm}^{2}$ and $380 \mathrm{~cm}^{2}$, respectively. Under impact of two projectiles with velocity $354.7 \mathrm{~m} / \mathrm{s}$ and $782.3 \mathrm{~m} / \mathrm{s}$, respectively, the damage area in the front surface and rear surface of RCT1 are $2830 \mathrm{~cm}^{2}$ and $4300 \mathrm{~cm}^{2}$, respectively.

Stress wave will be generated in the honeycomb structure under projectile penetration, and the stress wave will travel in the structure, and reflected wave and transmission wave will form at the interface of a different medium [8]. The stress wave caused by projectile impact will propagate through the target, both in concrete and steel, and stress wave impedance of steel is larger than that of concrete. While the incident wave arrived at the interface of concrete and steel pipe, compressed reflection wave will be formed. Due to the interaction of newly formed compression wave with other waves, the tensile stress of concrete will be reduced. Therefore, stress of concrete in the hexagonal cell which gets in contact with the projectile is smaller than stress of concrete in other hexagonal cells. Stress of the steel tube in the hexagonal cell which gets in contact with the projectile is the largest and thus the concrete damage area is small. There 


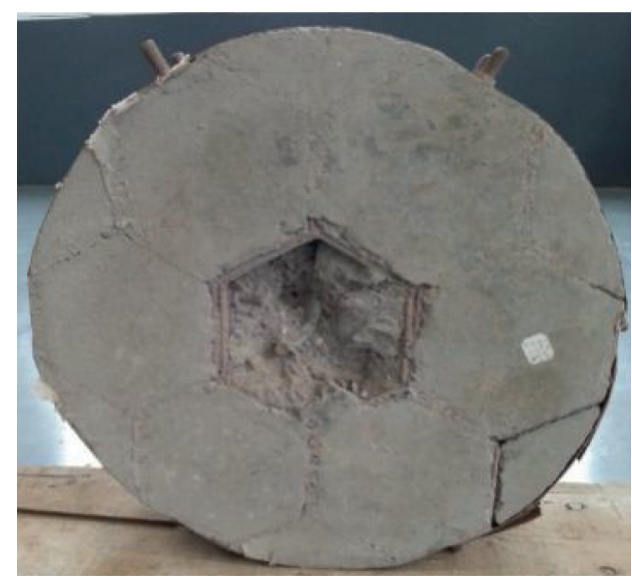

Front view

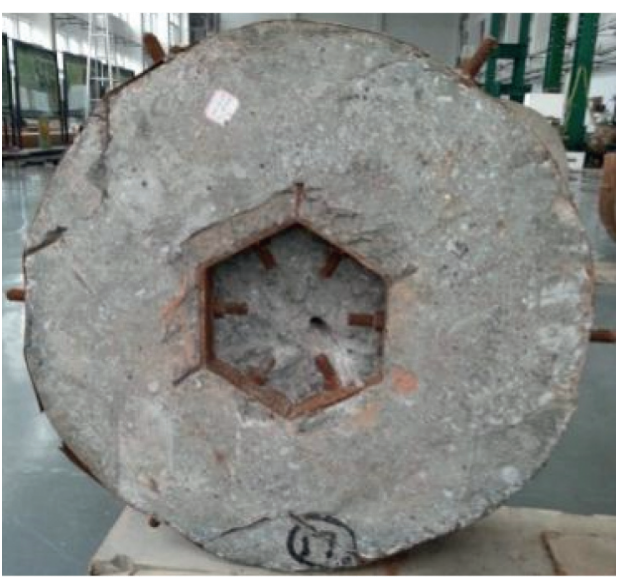

Front view

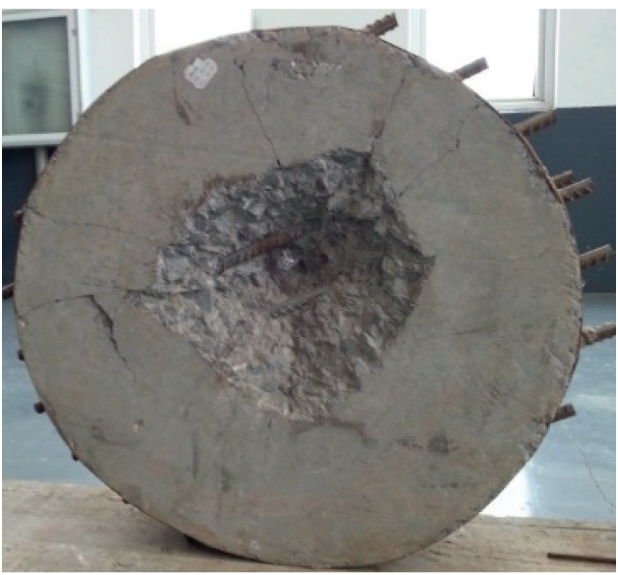

Front view

(b)

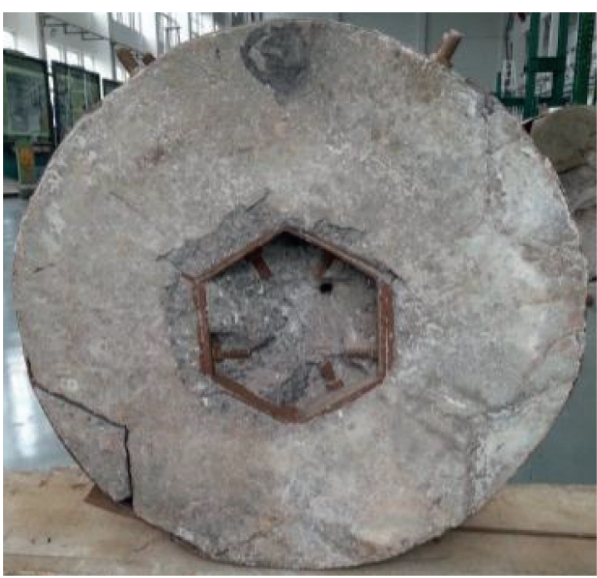

Rear view

(a)

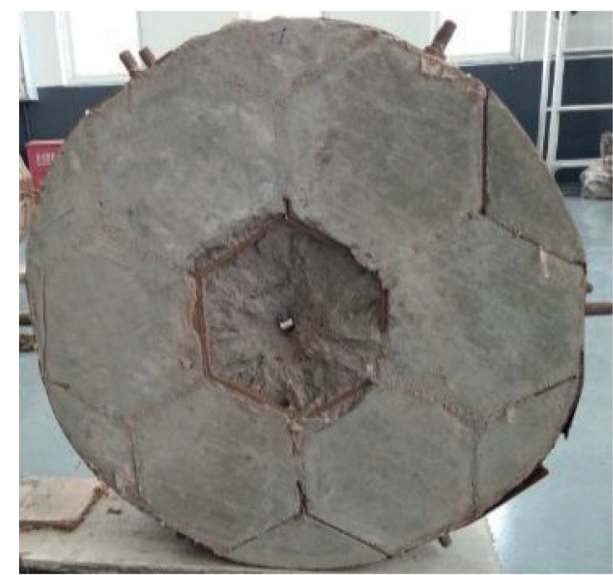

Rear view

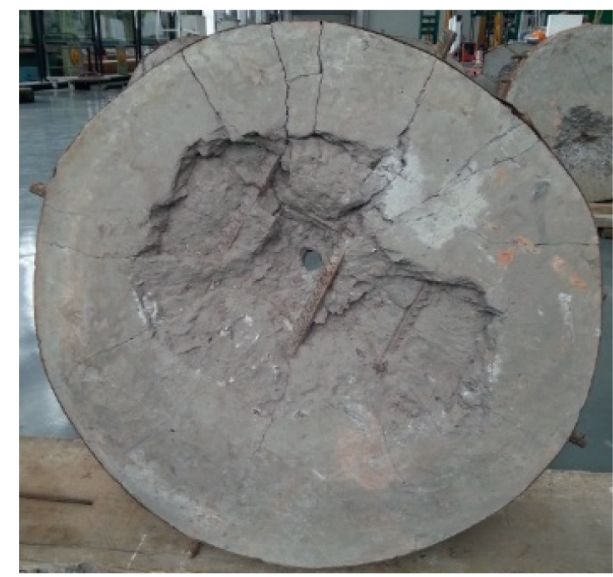

Rear view

(c)

FIgURE 7: Target after test: (a) HST1 front view and rear view, (b) HST2 front view and rear view, and (c) RCT1 front view and rear view.

are only two layers of reinforced bar in reinforced concrete target, and compression reflected wave will be produced while the incident wave propagation to the face of steel bar, so the reflected wave is less and thus the failure area of concrete in the reinforced concrete target is larger.
4.2. Analysis of Target Damage Range. As the experimental results show, the damage range of the honeycomb-structure target is greatly reduced compared with that of reinforced concrete target. Damage in the front surface of HST target is within the hexagonal cell which gets in contact with the 
TABLE 5: Configuration for FEM simulation.

\begin{tabular}{lcccc}
\hline $\begin{array}{l}\text { Configuration } \\
\text { set }\end{array}$ & Velocity of projectile 1 (m/s) & $\begin{array}{c}\text { Impact point location of } \\
\text { projectile 1 }\end{array}$ & $\begin{array}{c}\text { Velocity of projectile 2 (m/s) } \\
\text { Impact point location of } \\
\text { projectile 2 }\end{array}$ \\
\hline 1 & 400 & $0,0,0$ & 566 & $-30,0,200$ \\
2 & 566 & $0,0,0$ & 566 & $-30,-90,-200$ \\
3 & 566 & $-90,0,0$ & 566 & $90,0,200$ \\
4 & 783 & $-60,0,0$ & 783 & $-30,-60,400$ \\
\hline
\end{tabular}

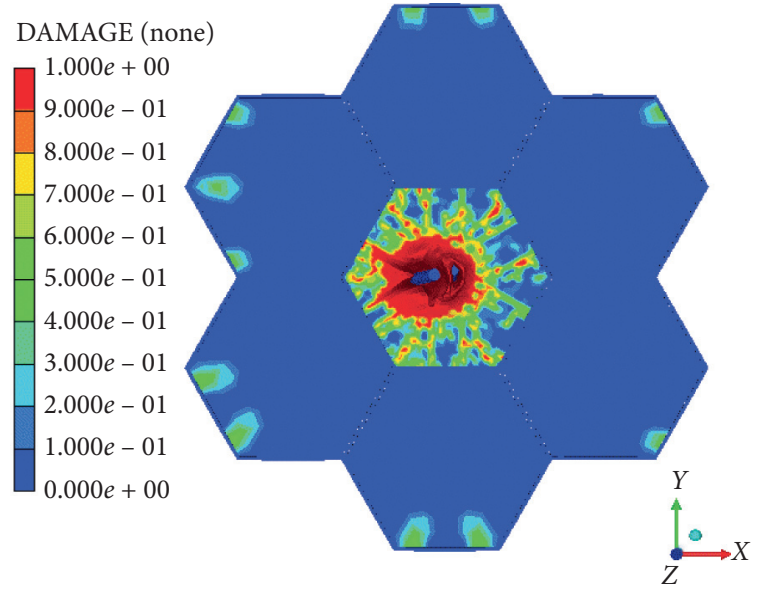

(a)

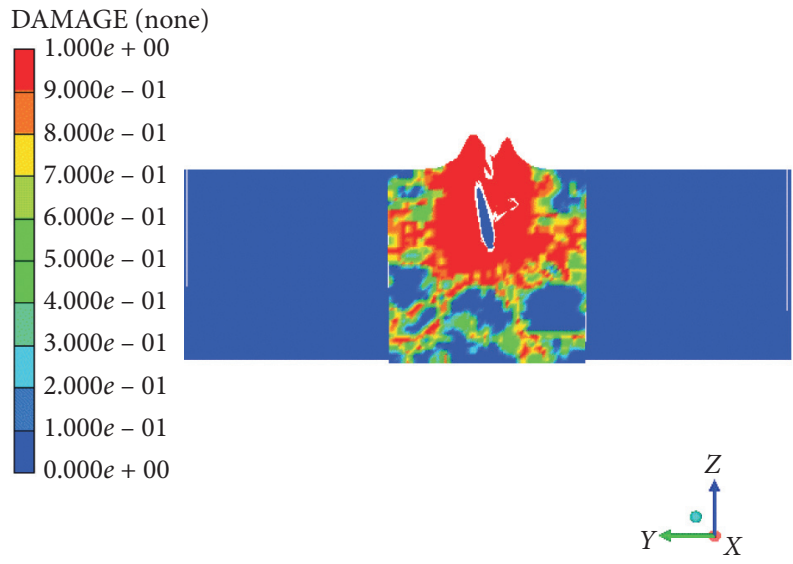

(c)

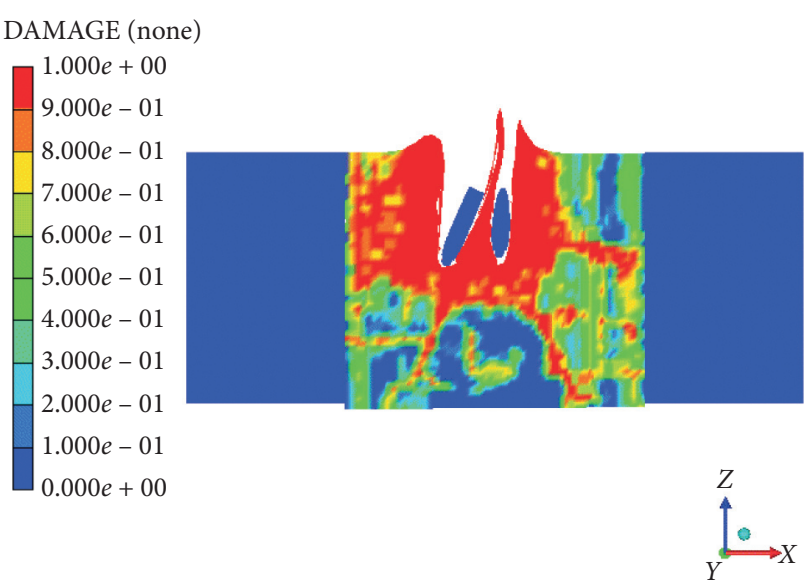

(b)

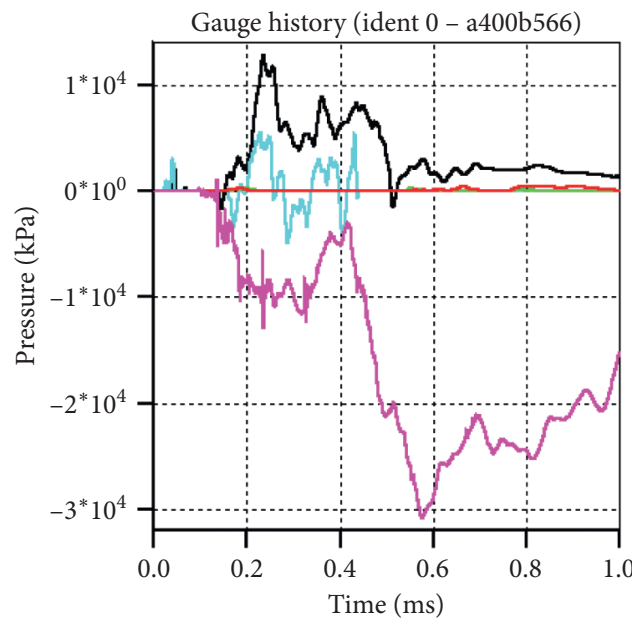

(1) Gauge\# $10-$ (4) Gauge\# 15
- (2) Gauge\# $11-$ (5) Gauge\# 18
(3) Gauge\# 14

(d)

FIgURE 8: Target damage under configuration set $1(t=1 \mathrm{~ms})$ : (a) front view, (b) section view by XZ plane, (c) section view by YZ plane, and (d) gauge history.

projectile, and there is no damage in other cells. The funnel pit in the rear surface is also within the hexagonal cell which gets in contact with the projectile and no damage occur in other cells. There is a funnel pit in the area which gets in contact with the projectile and radial cracks extend to the whole target. The numerical simulation results also show that damage in the HST target are within the hexagonal cell which gets in contact with the projectile and there is no damage in other cells.
When the stress wave propagates to the free surface of the honeycomb-structure target, namely, the upper and lower surfaces of the concrete-filled steel tube cell, tensile wave will be generated as the wave impedance of air is smaller than that of the concrete or steel pipe. The tensile wave reflected and incident wave will superimpose over one another and tensile stress will be formed in the free surface of the concrete-filled steel tube. If the tensile stress is greater than that of concrete, the concrete will be damaged and flake 


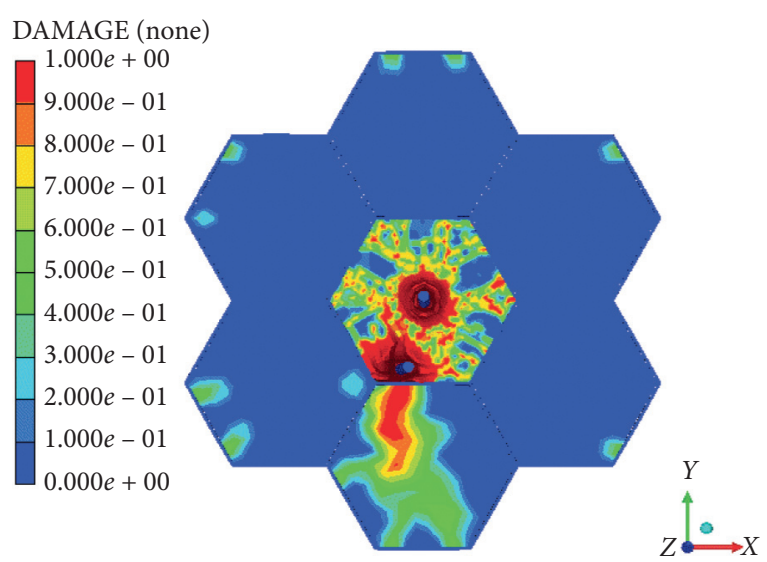

(a)

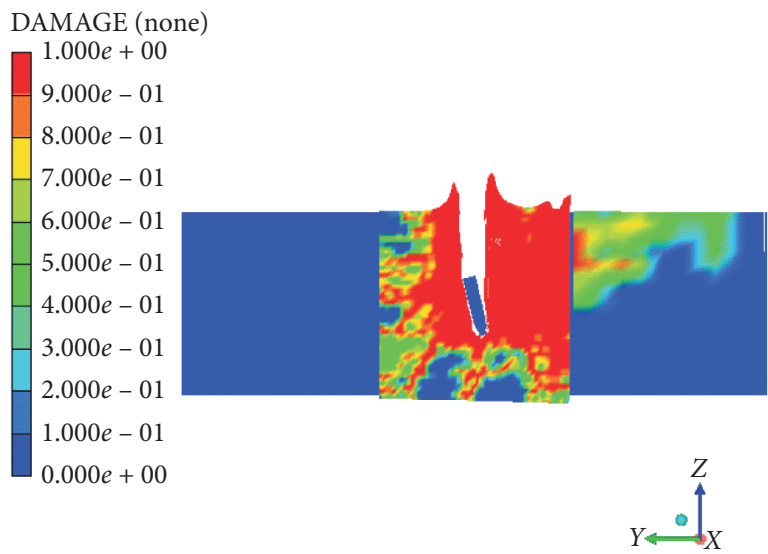

(c)

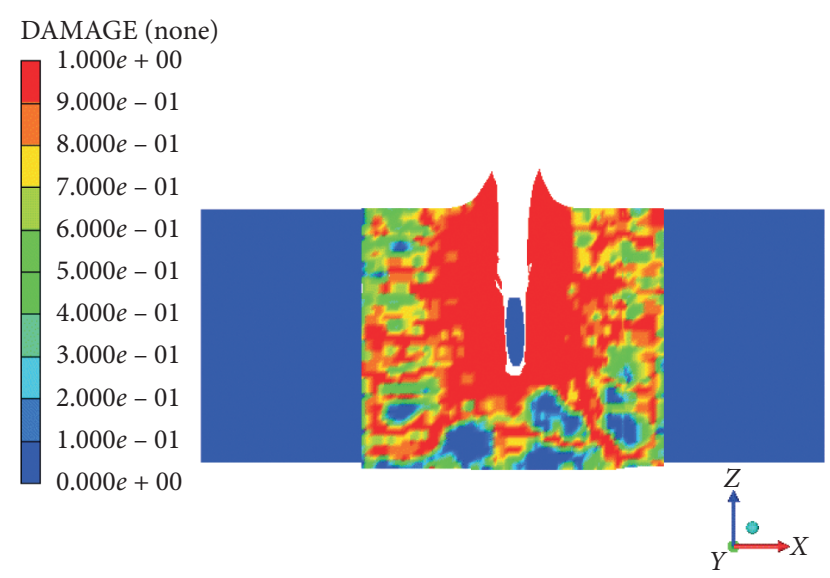

(b)

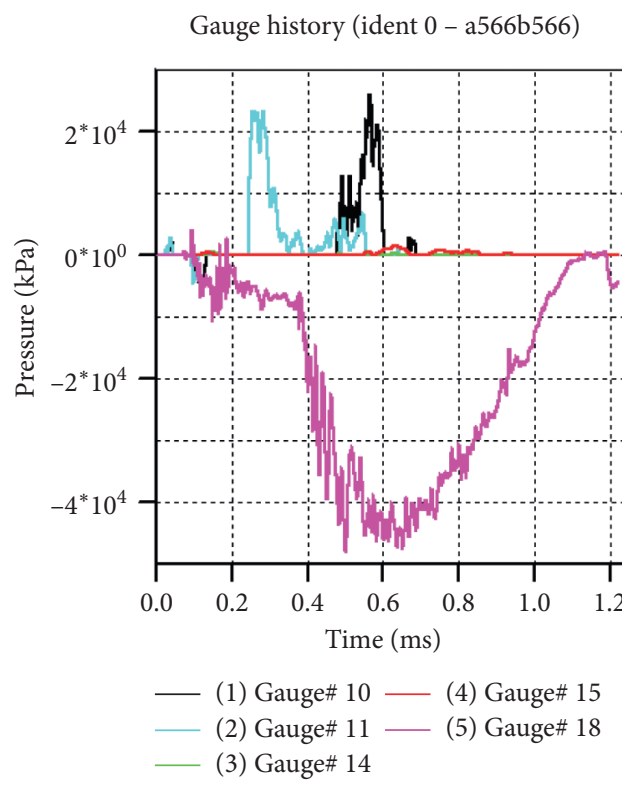

(d)

Figure 9: Target damage under configuration set $2(t=1 \mathrm{~ms})$ : (a) front view, (b) section view by XZ plane, (c) section view by YZ plane, and (d) gauge history.

or spallation will form, but the steel pipe will not peel off at the free face because of the high tensile strength of steel. New free surface will form after the formation of the first layer of concrete spallation, and then, with the penetration of the projectile, the tensile wave will form at the new free surface and will result in a new layer of spallation. All those explain the formation of impact crater and collapse crater in HST. Impact crater and collapse crater will also form in reinforced concrete targets, but the range is larger than that of the honeycomb-structure target. It is mainly due to the existence of the steel pipe in the honeycomb structure. The HST target is divided into several hexagonal cells by the steel tube, and thus wave propagation will undergo multiple reflection and transmission in the target. Damage caused by the stretch wave is limited within the hexagonal cell which gets in contact with the projectile due to the barrier effect of the steel tube. The stretch wave in other cells is smaller than the wave caused by the projectile or target, so no damage forms in other cells. In the reinforced concrete target, the damage range is larger for there is no barrier effect of the steel tube.

4.3. Deflection of Projectile. As two projectiles strike the target in the same cell successively, the deflection of the first projectile is the same as that in single projectile strike and the deflection is related to the contact location. the deflection of the second projectile is larger than that of the first projectile and it is related to the distance between the first contact location and the second contact location. While the distance is smaller, the deflection of the second projectile will be larger. The concrete damage degree is different and the strength decreases when the first projectile penetrates the target. While the second projectile penetration into the same cell, its deflection will be influenced by the concrete around with uniform strength. The projectile body is under 


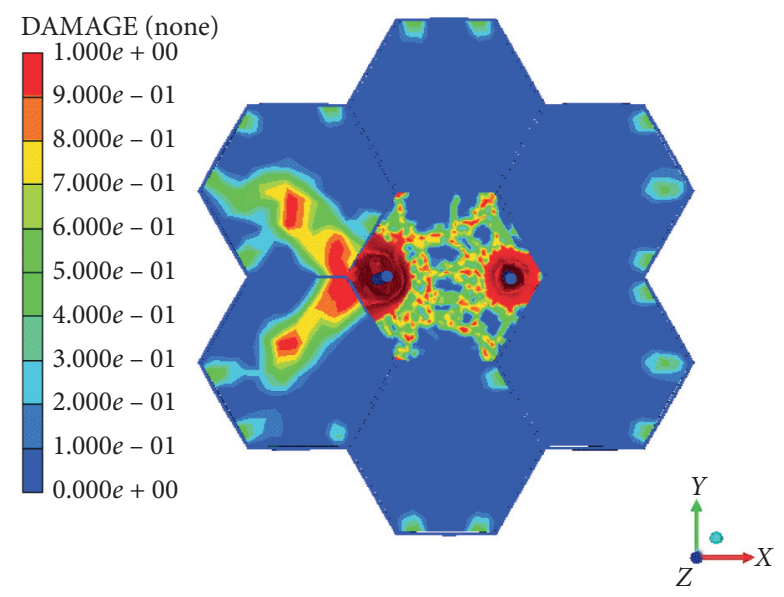

(a)

DAMAGE (none)

$1.000 e+00$
$9.000 e-01$
$8.000 e-01$
$7.000 e-01$
$6.000 e-01$
$5.000 e-01$
$4.000 e-01$
$3.000 e-01$
$2.000 e-01$
$1.000 e-01$
$0.000 e+00$

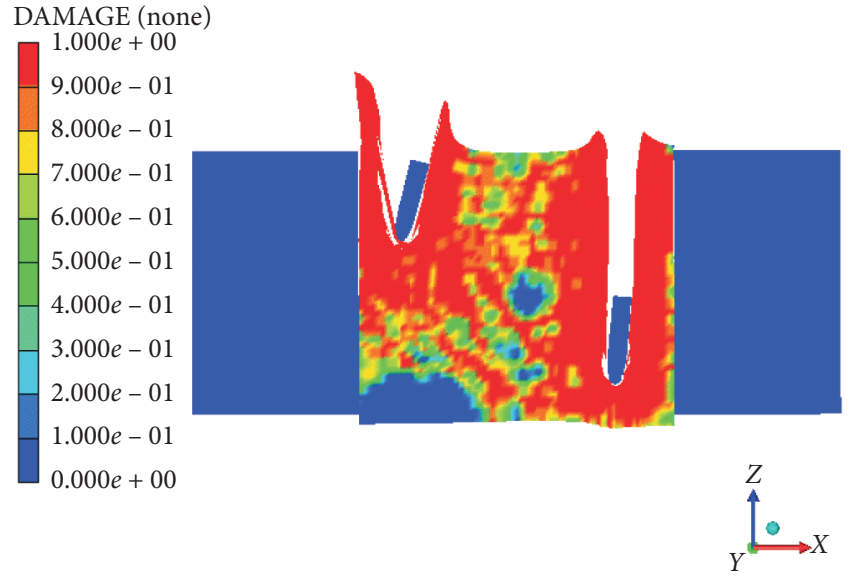

(b)

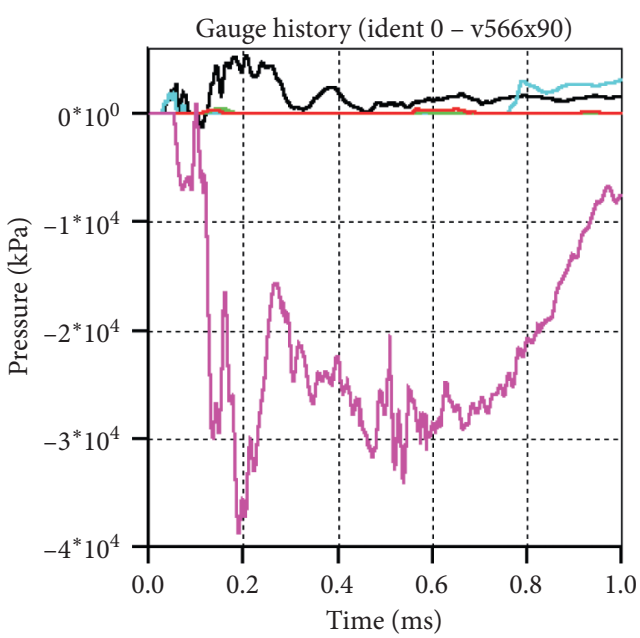

(1) Gauge\# $10-$ (4) Gauge\# 15
(2) Gauge\# $11-$ (5) Gauge\# 18
(3) Gauge\# 14

(c)

(d)

Figure 10: Target damage under configuration set 3 ( $t=1 \mathrm{~ms}$ ): (a) front view, (b) section view by XZ plane, (c) section view by YZ plane, and (d) gauge history.
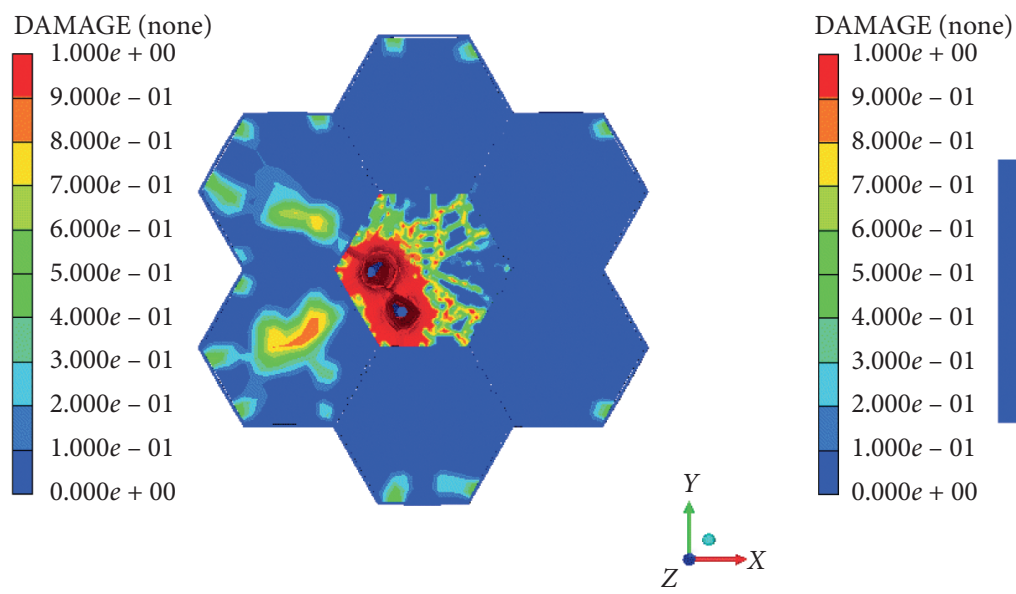

(a)

FIgure 11: Continued. 


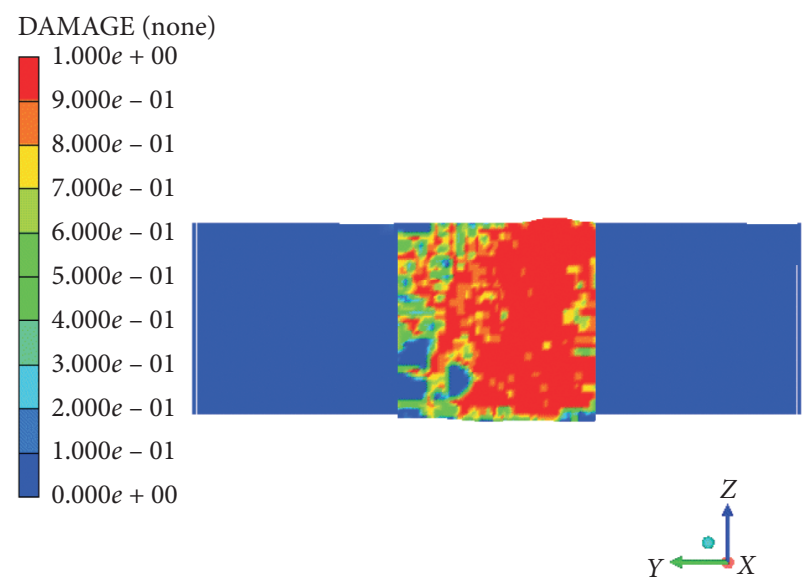

(c)

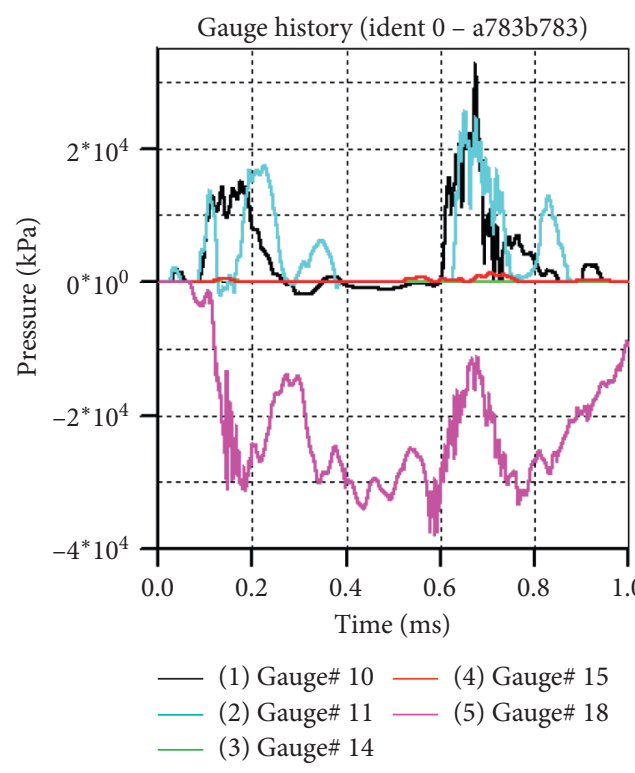

(d)

FIgURe 11: Target damage under configuration set 4 ( $t=1 \mathrm{~ms}$ ): (a) front view, (b) section view by XZ plane, (c) section view by YZ plane, and (d) gauge history.

asymmetric force during the penetration process, so it will undergo a large deflection.

\section{Conclusion}

(1) Under two repeat projectile strikes, the damage area of the honeycomb-structure target is smaller than that of the reinforce-concrete structure because compressive strength and deformation capacity of the concrete in the honeycomb structure get improved by the steel tube.

(2) Under two repeat projectile strikes, the damage range of the honeycomb-structure target is limited within the hexagonal cell which gets in contact with the projectile due to the barrier effect of the steel tube.

(3) During the two repeat projectile strikes, the first projectile will deflect to some extent just as single projectile strike. The deflection of the second projectile is larger and is related to the distance between the strike point of the two projectiles.

(4) Honeycomb shelter performs good under two repeat projectile strikes.

\section{Data Availability}

The data used to support the findings of this study are included within the article.

\section{Conflicts of Interest}

The authors declare that they have no conflicts of interest.

\section{Authors' Contributions}

Qifan Wang carried out the whole experiment and wrote the paper. Liuheng Chu designed the experiment and determined the whole structure of the paper. Jie Li carried out finite element modeling and checking calculation. Jianhu Sun carried out numerical simulation and analysis. Sheng Luo recorded and sorted out the data of repeated strike test. Lei Mao searched the relevant literature in the past five years, made corresponding revisions in the article, and helped to check grammatical errors in the text.

\section{Acknowledgments}

This project was supported by the Science and Technology Research Project of Chongqing Education Commission (no. KJZD-K201912902), China.

\section{References}

[1] G. Ren, Z. Mu, R. Liu et al., Penetration Effect and Engineering Protection of Precision Guided Weapons, Science Press, Beijing, China, 2016.

[2] Z. Wang, Y. Li, and Y. Huang, "Parameter determination of $\mathrm{JH}-2$ model and numerical analysis of repeated penetration of granite," Journal of Harbin Institue of Technology, 2019.

[3] G. Deng and X. Yang, "Numerical simulation analysis of multi projectile repeated strike effect in engineering rock," Explosion and Shock, vol. 34, no. 3, pp. 361-366, 2014.

[4] L. Hu, F. You, and T. Yu, "Effect of cell-wall angle on the inplane crushing behaviour of hexagonal honeycombs," $M a$ terials \& Design, vol. 46, pp. 511-523, 2013.

[5] S. Shi, Y. Liu, P. Yin et al., "New research on shock and explosion protection structure," Journal of Logistical Engineering College, vol. 20, no. 3, pp. 9-11, 2004. 
[6] S. Shi, X. Huang, Y. Liu et al., "Application of polygonal concrete-filled steel tube short component in protection engineering," Concrete, vol. 2005, no. 2, pp. 95-98, 2005.

[7] S. Shi, Q. Wang, Y. Liu et al., "Study on anti penetration mechanism and numerical simulation of bionic cellular shield," Protection Engineering, vol. 35, no. 4, pp. 45-49, 2013.

[8] Q. Wang, S. Shi, Z. Wang et al., "Experimental study on penetration of projectile through a honeycombed shield layer," Explosion and Shock, vol. 36, no. 2, pp. 253-258, 2016.

[9] Y. Xiong, J. Chen, Y. Hu et al., "Study on key parameters of concrete Johnson-Holmquist constitutive model," Engineering Mechanics, vol. 29, no. 1, pp. 121-127, 2012.

[10] X. Chai, Because of the Concrete Target Head Shaped on the Penetration Effect, Beijing Institute of Technology, Beijing, China, 2014.

[11] R. Zhang, Y. Ding, W. Tang et al., "Failure strength parameters of concrete HJC and RHT constitutive models," Proceedings of the High Pressure Physics, vol. 25, no. 1, pp. 15-22, 2011.

[12] Chinese Standard (2015), Code for Design of Concrete Structures (GB50010-2010), China Architecture \& Building Press, Beijing, China, 2015. 